\title{
Accumulated lifecourse adversities and depressive symptoms in later life among older men and women in England: a longitudinal study
}

\author{
Jane Falkingham ${ }^{1 \star}$, Maria Evandrou ${ }^{1,2}$, Min Qin ${ }^{1,2}$ and Athina Vlachantoni ${ }^{1,2}$ \\ ${ }^{1}$ ESRC Centre for Population Change, University of Southampton, Southampton, UK and ${ }^{2}$ Centre for \\ Research on Ageing, University of Southampton, Southampton, UK \\ ${ }^{*}$ Corresponding author. Email: j.c.falkingham@soton.ac.uk
}

(Accepted 19 March 2019; first published online 25 April 2019)

\begin{abstract}
This paper investigates the association between accumulated major lifecourse adversities and later-life depressive symptoms among older people in England, both at a single point in time (prevalence) and the onset over time during later life (incidence), using data from the English Longitudinal Study of Ageing. Using retrospective data on the experience of major life adversities from childhood onwards, five latent classes were identified: no/few lifecourse adversities (58.6\%), lost relationship (27.0\%), chained adversities (2.4\%), childhood adversities (6.3\%) and war-related adversities (5.7\%). Older people who had experienced 'chained adversities', 'childhood adversities' and 'a lost relationship' had higher odds of presenting current depressive symptoms in 2006, even after controlling for socio-demographic characteristics, health-risk behaviours and social resources. Longitudinal analysis indicated that amongst respondents who were clear of depression in 2006, those older people who had experienced childhood adversities, a lost relationship and war-related adversities experienced a higher risk of having a new case of depressive symptoms. Results further indicate that women's mental health in later life is more sensitive to earlier life adversities than men's. The study shows that intervention earlier in the lifecourse may have benefits for the individual both contemporaneously and over the longer term.
\end{abstract}

Keywords: adversity; lifecourse; depression; England

\section{Introduction}

Depression is the most common mental disorder in later life, affecting people's quality of daily life and functioning. It can be experienced as a result of stress initiating cognitive and biological processes; with major life adversities, traumatic events or lifecourse adversities (terms often used interchangeably) being found to be amongst the best predictors of future onset of depression (Kraaij et al., 2002). 
Despite the fact that there are now more people in the United Kingdom (UK) aged 60 or over than aged under 18 (Office for National Statistics (ONS), 2017), and that by mid-2039 more than one in 12 of the population is projected to be aged 80 or over (ONS, 2015), relatively few studies have examined the impact of major lifecourse adversities amongst the older population. Even fewer have taken a longitudinal approach, investigating the association between earlier life adversity with the onset or recurrence of depression in later life (e.g. Fiske et al., 2003), and there are none to our knowledge in the UK. This paper therefore adds to the literature in three important ways. Firstly, by taking a more holistic perspective of entire lifecourse adversities experience, it provides new evidence on the relationship between accumulated major life adversities and depressive symptoms amongst communitydwelling older people aged 50 and over in England at a single point in time (2006). Secondly, it provides new insights into the persistent effect of major life adversities as a risk factor for the onset of depression during later life, following older individuals who are clear of depression at the baseline over an eight-year period (20062014). Finally, it evidences the differences of such relationships by gender.

\section{Depression in old age and gendered patterns}

The level of depression in old age varies due to differences in diagnostic criteria and the population sampled between studies. Based on the estimation of the World Health Organization (2017), globally, the depression prevalence rate was 4.4 per cent in 2015 and varied by age, peaking among those aged 55-74 years (above $7.5 \%$ among females, and above 5.5\% among males). Blazer (2003) reviewed the existing evidence of depression in late life and reported that major depressive disorder occurs among up to 4 per cent of community-dwelling older adults aged 65 and above, and minor depression among 8-16 per cent. In the UK, the 2014 Adult Psychiatric Morbidity Survey using the Clinical Interview Schedule-Revised reported that among people aged 16, the prevalence of depression was 3.3 per cent, and that depression was more common in people aged 16-64 than in those aged 65 and above (McManus et al., 2016). Existing research shows that biological, psychological and social factors, such as medical illness, genetic susceptibility to mood disorders, endocrine changes, adverse life events and impaired social support, are all associated with later-life depression (Blazer, 2003).

Women are about twice as likely as men to develop depression during their lifetime, with a higher recorded prevalence in older women than in older men. Certain unique biological and social factors likely contribute to women's higher prevalence of depression (Nolen-Hoeksema, 2001). Women have historically had less socioeconomic power and status than men due to patterns of financial dependence or economic standing, and are also more likely to experience chronic strains, such as poverty and constrained choices (Stone et al., 2013). Moreover, women experience certain traumatic events, particularly sexual abuse, more often than men. A recent epidemiology survey of traumatic-event exposure worldwide (Kessler et al., 2017) shows that most people (over 70\%) are exposed to traumas at some time in their life and nearly one-third were exposed to four or more traumas. In addition, men and women differ in the types of events they tend to experience, with men being more likely to report injuries, accidents and physical assault, and 
women more likely to report sexual assault. Even when women and men experience the same stressors, women may be more likely than men to develop depression (Breslau et al., 1997). Studies have found that gender roles and psychological factors are more important than biological factors in explaining gender differences in stress responses (Nazroo et al., 1997; Lundberg, 2005).

\section{The impact of early life adversities and health}

Early life adversity has been associated with a life-long increased risk for ill health. O'Rand and Hamil-Luker (2005) found that early disadvantage and childhood illness have severe enduring effects and increase the risk for heart attack across the lifecourse. Friedman et al. (2015) reported an association between early life adversity, such as childhood abuse and allostatic load, which is a marker of biological risk induced from inflammation, cardiovascular function, lipid metabolism and other indicators. A further recent study found that childhood abuse is linked to earlier all-cause mortality among women but not among men (Chen et al., 2016). Other studies have examined the effect of mediating factors such as personality traits and personal control, between early life events and later-life health outcomes. For instance, Pitzer and Fingerman (2010) found that higher levels of personal control were associated with better physical and psychological functioning among adults who experienced abuse in childhood. However, such studies have focused solely on the effects of early childhood adversities, without exploring the full range of lifecourse adversities.

The association between major life adversities and depressive symptoms is now relatively well established. A number of studies among psychiatric patients and the general population have explored the long-term effects of traumatic stress on current adult depression, showing consistently that adults with depression report early traumatic adversities, such as experience of war (Landau and Litwin, 2000), natural disasters (Briere and Elliot, 2000), sexual assault (Zoellner et al., 2000), bereavement (Utz et al., 2012) and childhood traumas (Nurius et al., 2015). Several mechanisms have been proposed; for instance, it is argued that stressful events may cause negative affective states such as feelings of anxiety, which in turn exert direct effects on biological processes or behavioural patterns influencing disease risk (McEwen, 1998). Over time, dysregulations across major biological regulatory systems (cumulative interacting adverse effects) may influence physiological and neuro-immunological pathways linking mental and physical health (Slavich and Irwin, 2014).

\section{Theoretical background and empirical studies of early life adversities and later-life depression}

The mechanisms between major adversities earlier in the lifecourse and health in later life are, however, less clear cut. Evidence of a causal link between two phenomena distant in time is more difficult to uncover due to the presence of multiple confounding factors in the intervening period, although the reciprocal effects of social, biological and psychological systems on each other are known to play an important 
role. Two inter-related theoretical approaches help to frame conceptually the experience of traumatic/stressful lifetime events and their relationship with depressive symptoms in later life - the theory of 'stress proliferation' (Pearlin et al., 2005) and the 'cumulative inequality' theory (Ferraro and Shippee, 2009).

Pearlin et al. (2005) put forward a conceptual framework regarding 'stress, health and the lifecourse', arguing that inequality rooted in social structure accumulates across an individual's lifespan, and that disadvantaged individuals have the greatest chance of exposure to health-related stressors. This is consistent with much of the literature on health inequalities, recognising that some groups have better opportunities for good health and longevity than others (Wilkinson and Pickett, 2009). Importantly, for the purpose of this paper, and in addition to highlighting the potential health effects of single long-term stressors, such as poverty or discrimination, Pearlin et al. (2005) also put forward the notion of stress proliferation as a mechanism to explain how earlier life circumstances can affect later health and wellbeing. They suggest that early traumas and off-time or out-ofsequence transitions (i.e. major life adversities), tend to give rise to additional, or secondary, stressors. Thus, those individuals who were exposed to a (early) serious adversity are at risk of experiencing a later exposure to additional adversities, which in turn cause cumulative, long-term harm to health (Horwitz et al., 2001).

The cumulative inequality theory adds a further dimension, contending that cumulative inequality interacts with one's ability to mobilise social, economic and psychological resources, shaping the individual's health and wellbeing in old age (Ferraro and Shippee, 2009). Individuals with early life traumas are thus more likely to encounter and generate further stressful events throughout the later lifestages, but with fewer personal and psycho-social resources to cope with them. Moreover, such individuals are more likely to amplify their biological and emotional response to any later-emerged stressor and are predisposed to selfmedicating behaviours like smoking, drug use and consumption of high-fat diets (Nusslock and Miller, 2016). Together, these contributions to the literature provide a useful base to develop a conceptual framework which links the experience of stressful events at one stage of the lifecourse with adverse outcomes at a subsequent stage (Figure 1).

Some researchers argue that the consequences of prior adversities are better captured by considering one's exposure to multiple events rather than to one focal event only (Green et al., 2000), a position which is consistent with the concept of stress proliferation and lifetime cumulative adversity. A study analysing data from the Survey of Health, Ageing and Retirement in Europe found that respondents with more lifetime cumulative adversities were at greater risk of a high level of depressive symptoms and low quality of life (Shrira, 2012). The association between cumulative adversities and mental health has also been explored taking into account differences in the type of adversity and gender. For instance, studies found that self-oriented adversities (i.e. those reflecting trauma where the individual themselves was the target, e.g. being at risk of death due to accident or being a victim of assault or abuse) had a positive association with depressive symptoms, whereas other-oriented adversities (i.e. those where the trauma came from being exposed to actions targeting others, e.g. witnessing people killed by violence) had either no association or an inverse association with depressive symptoms 


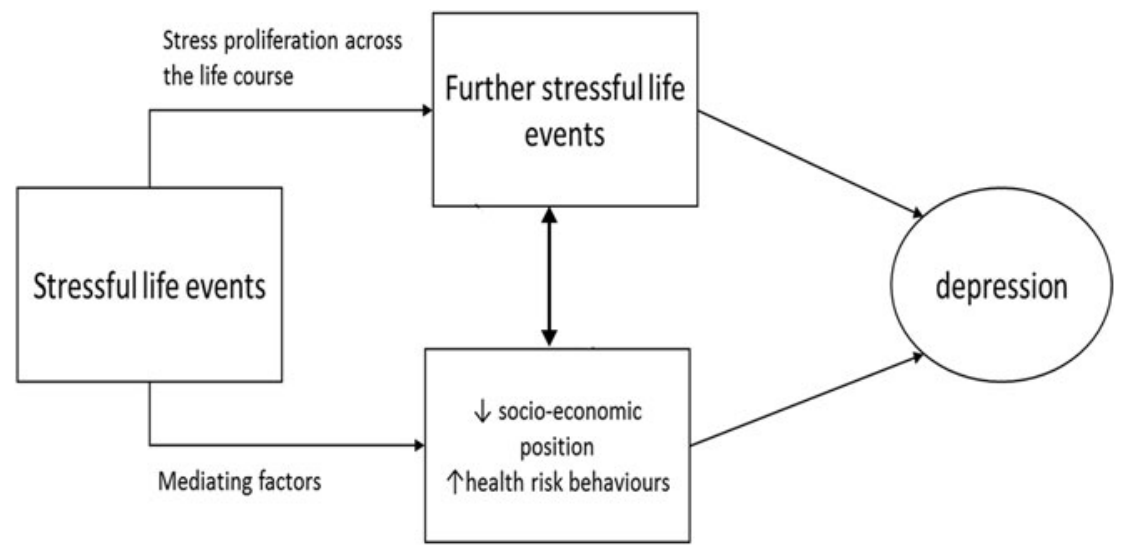

Figure 1. Conceptual framework linking the experience of stressful events at one stage of the lifecourse with adverse outcomes at a subsequent stage.

Source: Authors' conceptualisation.

(Shmotkin and Litwin, 2009). However, Palgi et al. (2012) showed that both selforiented and other-oriented lifetime traumatic events were associated with perceived loneliness and depressive symptoms in the second half of individuals' life.

\section{Research hypotheses}

Few studies have explored holistically the dimensions of entire lifecourse adversities experience (Pietrzak and Cook, 2013), and whether such adversities continue to be associated with a later risk of depressive symptoms, either as a first onset or as an episode recurrence. This paper aims to (a) create and describe a taxonomy of the clustered lifecourse adversities among older men and women in England, and (b) investigate the association between these lifecourse adversities and mental health in later life. The first two hypotheses of this study are formulated as follows:

- Hypothesis 1: The risk of suffering depressive symptoms in later life is higher amongst those who have suffered accumulated lifecourse adversities than those who have not (retrospective combined with cross-sectional analysis).

- Hypothesis 2: This effect persists into later life (longitudinal analysis).

Moreover, our understanding of the association between major adversities during the lifecourse and their adverse impact on individuals' mental health in later life cannot be isolated from gender differences permeating individuals' social and financial resources across the lifecourse (Pearlin et al., 2005). Women in particular in many societies experience a relative lack of social power, making them more vulnerable than men to specific traumas, which in turn may contribute to depression directly or indirectly by increasing women's reactivity to stress (Nolen-Hoeksema, 2001). For instance, Pirkola et al. (2005) found that among a population sample aged 30-64 in Finland, there were marked sex differences in the associations between reported childhood experiences and environmental circumstances, on 
the one hand, and adulthood mental disorders, on the other. We therefore further hypothesise the sex differences in the associations as follows:

- Hypothesis 3: Women's mental health in later life is more sensitive to earlier life adversities than men's.

\section{Method}

\section{Data}

This study analysed data from the English Longitudinal Study of Ageing (ELSA), which started in 2002 and collects information on physical and mental health, as well as demographic and socio-economic circumstances, from a representative sample of the English population aged 50 years and over (Marmot et al., 2016). The sample has been followed up with an interview and medical examination every two and four years, respectively (Steptoe et al., 2012). At Wave 3 in 2006, an additional module collecting retrospective life-history data was fielded (Ward et al., 2009). Given this paper focuses on measures of lifetime adversities, the analyses were based on Wave 3 (2006) which was taken as the study baseline, with follow-up at Wave 4 (2008), Wave 5 (2010), Wave 6 (2012) and Wave 7 (2014).

\section{Study sample}

A total of 7,855 participants completed the ELSA Wave 3 (2006) life-history interviews. Of these, 7,048 were core study members and were aged 50 and above. From this sample, a total of 1,821 respondents were excluded from the analysis because of missing values (not mutually exclusive) on adversity events $(\mathrm{N}=1,807)$, childhood health $(\mathrm{N}=7)$, housing wealth $(\mathrm{N}=7)$, physical activity $(\mathrm{N}=8)$ and depressive symptoms $(\mathrm{N}=29)$. Missing values for alcohol intake and social isolation were categorised as a missing group. The final analytical sample was 5,198 ( $\operatorname{men}=2,330$, women $=2,868)$, which was classified into four age groups: 50-59 (29.6\%), 60-69 (33.5\%), 70-79 (25.8\%) and 80 and above (11.1\%). The majority of respondents $(84.8 \%)$ had intermediate or high education. More information about the sample $(\mathrm{N}=5,198)$ is provided in Table 1 . This sample was used for the cross-sectional analysis. The analysis of the excluded participants shows that they were more likely to experience significant depressive symptoms $(18.2 \%$ versus $13.0 \%, p=0.001)$ and were older than the analytical sample (mean age 67.2 versus $66.3, p=0.001$ ), but there were no gender differences (see Table S1 in the online supplementary material).

Cross-sectional analysis can only analyse multiple variables at a given time, however, depressive symptoms might have occurred prior to some of the adversities. In order to avoid a possible reverse time-order between the lifecourse adversity and depression, participants with current depressive symptoms at the baseline were excluded and 4,520 respondents who were clear of depressive symptoms in 2006 were selected to follow up in the longitudinal analysis. Among them, 479 participants who had missing information on the measurement of depressive symptoms in all of the follow-up surveys from Wave 4 (2008) to Wave 7 (2014) were excluded. Thus, the total analytical sample for the longitudinal analysis was 4,041 . 
Table 1. Bivariate associations between selected covariates and depressive symptoms

\begin{tabular}{|c|c|c|c|}
\hline Variables and categories & $\begin{array}{c}\text { Percentage of significant } \\
\text { depressive symptoms (depression) }\end{array}$ & $p$ & Cases \\
\hline Depressive symptoms present & 13.0 & & 5,198 \\
\hline \multicolumn{4}{|l|}{ Lifecourse adversities: } \\
\hline No/few chances of adversities & 10.0 & 0.000 & 3,044 \\
\hline Relationship lost & 16.0 & & 1,404 \\
\hline Chained adversities & 40.0 & & 125 \\
\hline Childhood adversities & 18.3 & & 327 \\
\hline War-related adversities & 13.1 & & 298 \\
\hline \multicolumn{4}{|l|}{ Age group: } \\
\hline $50-59$ & 14.5 & 0.016 & 1,539 \\
\hline $60-69$ & 11.2 & & 1,743 \\
\hline $70-79$ & 12.9 & & 1,341 \\
\hline $80+$ & 15.1 & & 575 \\
\hline \multicolumn{4}{|l|}{ Sex: } \\
\hline Male & 10.0 & 0.000 & 2,330 \\
\hline Female & 15.5 & & 2,868 \\
\hline \multicolumn{4}{|l|}{ Current marital status: } \\
\hline Never married & 14.8 & 0.000 & 277 \\
\hline First marriage & 9.0 & & 2,929 \\
\hline Remarried & 9.4 & & 608 \\
\hline Divorced & 23.5 & & 544 \\
\hline Widowed & 22.4 & & 840 \\
\hline \multicolumn{4}{|l|}{ Childhood self-rated health: } \\
\hline Good & 11.9 & 0.000 & 4,578 \\
\hline Fair/poor & 21.5 & & 620 \\
\hline \multicolumn{4}{|l|}{ ADL difficulties: } \\
\hline None & 9.5 & 0.000 & 4,279 \\
\hline One item & 23.2 & & 499 \\
\hline Two or more items & 37.4 & & 420 \\
\hline \multicolumn{4}{|l|}{ Education: } \\
\hline Low ( $\leqslant 14$ years) & 17.0 & 0.000 & 792 \\
\hline Intermediate (15-16 years) & 14.5 & & 2,861 \\
\hline High ( $\geqslant 17$ years) & 8.3 & & 1,545 \\
\hline
\end{tabular}


Table 1. (Continued.)

\begin{tabular}{|c|c|c|c|}
\hline Variables and categories & $\begin{array}{c}\text { Percentage of significant } \\
\text { depressive symptoms (depression) }\end{array}$ & $p$ & Cases \\
\hline \multicolumn{4}{|l|}{ NS-SEC: } \\
\hline Higher managerial/professional & 8.5 & 0.000 & 1,785 \\
\hline Intermediate & 12.7 & & 1,358 \\
\hline Routine/manual & 17.3 & & 1,997 \\
\hline Long-term unemployed & 15.5 & & 58 \\
\hline \multicolumn{4}{|l|}{ Housing wealth $(£)$ : } \\
\hline None & 27.3 & 0.000 & 812 \\
\hline $1-149,999$ & 15.8 & & 990 \\
\hline $150,000-299,999$ & 10.1 & & 2,166 \\
\hline $300,000-449,999$ & 8.1 & & 805 \\
\hline $450,000+$ & 3.8 & & 425 \\
\hline \multicolumn{4}{|l|}{ Smoking status: } \\
\hline Never smoked & 11.2 & 0.000 & 2,065 \\
\hline Current smoker & 22.1 & & 670 \\
\hline Former smoker & 12.1 & & 2,463 \\
\hline \multicolumn{4}{|l|}{ Drinking status: } \\
\hline$<$ Daily & 8.2 & 0.000 & 817 \\
\hline Daily & 13.0 & & 3,903 \\
\hline Missing & 22.0 & & 478 \\
\hline \multicolumn{4}{|l|}{ Physical activity: } \\
\hline Low & 21.9 & 0.000 & 1,510 \\
\hline Moderate & 10.3 & & 2,650 \\
\hline High & 7.2 & & 1,038 \\
\hline \multicolumn{4}{|l|}{ Work status: } \\
\hline Not retired & 13.7 & 0.216 & 2,481 \\
\hline Retired & 12.5 & & 2,717 \\
\hline \multicolumn{4}{|l|}{ Social isolation: } \\
\hline Low & 7.1 & 0.000 & 1,430 \\
\hline Median & 11.7 & & 1,269 \\
\hline High & 22.8 & & 534 \\
\hline Missing & 15.6 & & 1,965 \\
\hline
\end{tabular}

Notes: $\mathrm{N}=5,198$. ADL: activity of daily living. NS-SEC: National Statistics Socio-economic Classification. Source: Authors' analysis of the English Longitudinal Study of Ageing, Wave 3 (2006).

Significance levels: ${ }^{\star} p<0.05,{ }^{\star \star} p<0.01,{ }^{\star \star \star} p<0.001$. 


\section{Measurement}

\section{Current depressive symptoms}

The Eight-Item Center for Epidemiologic Studies Depression Scale (CES-D) was used to measure depressive symptoms. The CES-D has been widely used in studies of later-life depression, and has good psychometric properties for use in the UK population (Karim et al., 2015). A cut-off point of 4 has been found to produce comparable results to other depression scales (Steffick, 2000). In the survey, in order to determine the presence of depressive symptoms, each respondent was asked the following questions, with the response options of 'yes' or 'no': (1) Much of the time during the past week I felt depressed; (2) I felt everything I did was an effort; (3) My sleep was restless; (4) I was happy; (5) I felt lonely; (6) I enjoyed life; (7) I felt sad; and (8) I could not 'get going'. For each respondent, the total number of yes responses to questions $1,2,3,5,7,8$, and the 'no' responses to questions 4 and 6 were summed to create a total depressive symptom score ranging from 0 to 8 . If an individual was missing any of the eight items, they were excluded from the analyses. In this study, the report of current depressive symptoms equals 1 if the respondents' total depressive symptom score is greater than, or equal to, four at the baseline in 2006; and it equals 0 if not. This measurement was treated as the dependent variable for the cross-sectional logistic regression models.

\section{Time until having a new case of depressive symptoms}

This time-to-event measurement was used as the dependent variable for the longitudinal Cox regression models. A group of participants $(\mathrm{N}=4,041)$ who were clear of depression at the baseline in 2006 were asked the CES-D questions in each of the follow-up interviews between 2006 and 2014. The time until having a new case of depressive symptoms was measured as the period from the baseline survey in 2006 when respondents were clear of depression to the year when the respondents' depressive symptoms occurred (total depressive symptom score greater than, or equal to, four). The score equals 1 if the respondents had significant depressive symptoms at Wave 4 (2008). The corresponding time equals 2, 3 or 4 if the new case of depressive symptoms happened at Wave 5 (2010) or Wave 6 (2012) or Wave 7 (2014), respectively.

\section{Accumulated lifecourse adversity}

Sixteen lifecourse adversities listed in the ELSA life-history questionnaire were used for the latent class analysis (LCA) method to generate the latent variable, reflecting the accumulation of major lifecourse adversities. Table S2 (in the online supplementary material) presents a list of the questions and the prevalence of each adversity by gender. Significant gender differences were observed for the majority of single adversities. Four out of 16 questions including the indication 'aged $<16$ ' helped to understand the timing of when such adversities were first experienced in childhood: 'Whether when aged $<16$ was physically abused by your parents; Whether when aged $<16$ parents argue or fight very often; Whether when aged $<16$ either parent was unemployed for over six months when wanted to work; Whether when aged $<16$ parents drunk/took drugs/had mental health problems'. Other adversities such as 'Ever fired a weapon in combat or been fired upon; 
Ever had a husband/wife/partner/child who has been addicted to drugs or alcohol' are likely to have been experienced during the respondents' adulthood. LCA was applied to identify latent classes (accumulated lifecourse adversity) for the next step of the statistical analysis.

\section{Control variables}

The multivariate analyses were performed after controlling for the effects of selected demographic, socio-economic status, risk behaviour and social resources variables, the selection of which was based on previous studies (Kessler et al., 1996; Blazer, 2003; Fiske et al., 2003). These controls included age, gender, current marital status, childhood self-rated health, activities of daily living (ADLs), education, National Statistics Socio-economic Classification (NS-SEC), housing wealth, smoking status, alcohol drinking status, working status, physical activity and social isolation.

\section{Analytical plan}

LCA was applied to identify unobserved sub-groups characterised by common lifecourse patterns of adversities experience. LCA is a model-based clustering method which produces the latent classes or latent clusters (terms used interchangeably) using a probabilistic model describing the distribution of data (Goodman, 2002). In contrast to other clustering approaches finding sequence clusters with a chosen distance measure (e.g. Stone et al., 2015), LCA helps to compare models with differing numbers of latent classes in order to determine the best-fitting model. The categorical indicators used for the LCA were 16 reported single lifecourse adversities (see Table S2 in the online supplementary material). We began with a two-class model and proceeded to test models with successively larger numbers of classes. The choice of the optimal number of classes was based on the comparison of various models using Akaike information criterion (AIC), Schwarz's Bayesian information criterion (BIC) and the sample-size-adjusted BIC (A-BIC), where a smaller AIC, BIC or A-BIC value indicates a better-fitted model. Further, we assessed the entropy of each model as an indicator for class separation, with higher entropy values being preferable, and performed the Lo-Mendell-Rubin likelihood ratio test (LMR), Vuong-Lo-Mendell-Rubin likelihood ratio test (vLMR) and bootstrap likelihood ratio test (bLRT) to test the significance of the difference in likelihoods of two models, where a non-significant $p$ value indicates that the model with one or fewer classes is preferable. The authors' judgement of model interpretability were considered in the final decision.

Once the optimal number of classes was determined, a three-step procedure was applied for modelling LCA with distal outcomes (Asparouhov and Muthén, 2014). Using a conventional regression model, treating the latent class membership as a directly observable variable may lead to biased results because it ignores the classification uncertainty that is attached to the process of extracting the latent class membership given the probabilistic nature of this method. A three-step procedure was therefore adopted to avoid any potential bias. The first step fitted a LCA model with the 16 categorical indicators of single lifecourse adversity only and assigned respondents to their mostly likely latent class $N$. The second step determined the measurement error for $N$. The third step estimated the logistic or Cox regression 
models, where the latent class variable was measured by the most likely class variable $N$, and the measurement error was fixed and prespecified to the values obtained from step 2. Mplus 8 was used for the statistical analysis (Muthén and Muthén, 2017).

In our analysis, there were two types of distal outcomes. The first was a binary variable - the current depressive symptoms at the baseline in 2006; the second was a 'time to event' variable - time to have new depressive symptoms during the follow-up, 2006-2014. LCA models with distal outcomes were run first for females and males together, and then for females and males separately. For the binary distal outcome logistic regression was used, which uncovers relationships between lifecourse adversity and the prevalence of depression. Given the cross-sectional nature of all variables measured at a single point in time, it is possible that depressed older people are more likely to report lifecourse adversities. In order to address the possible reverse time sequence between depressive symptoms and lifecourse adversities, we then conducted Cox regression analysis to examine the time to have a new case of depressive symptoms during the follow-up period from 2006 to 2014, taking the latent classes of the accumulated major lifecourse adversities into consideration. For this longitudinal analysis, older people with depression in the previous logistic regression were excluded and only those who were clear of depression at baseline in 2006 were included. Participants were right-censored at the end of observation in 2014 if they did not experience a new case of depressive symptoms. Those with missing measurements of depressive symptoms were also right-censored at the time of dropout.

The ELSA has a relatively high sample attrition rate (Banks et al., 2011). In the longitudinal analysis for this paper, 1,689 out of the total 4,520 respondents who were clear of depression at the baseline (Wave 3, 2006) only completed one, two or three rounds of the survey in the subsequent phases of data collection, and dropped out of the survey before 2014. As a result of such attrition, there may be possible selectivity affecting the validity of the results. There are two ways in which attrition can bias a sample (Ahern and Brocque, 2005). Firstly, attrition may alter the characteristics of the sample, making it no longer representative of the original sample. Secondly, selective attrition can bias the longitudinal data by altering the covariance of variables. This occurs when the under-representation of some groups in the longitudinal sample leads to correlations between variables that are different from the true correlations in the original data. In order to explore the latter, survival analysis was run to investigate whether any of our study variables had been affected by attrition, which in turn could change the true correlations in the study sample. Unlike logistic regression, survival analysis estimates the time until respondents drop out of the survey, capturing the features of both earlier and later drop-offs. This method has been used in previous studies to reveal significant predictors of longitudinal sample attrition (Zethof et al., 2016). The results show that all selected variables were not statistically different between the study cases and the cases either lost to follow-up or with missing values, indicating that attrition was at random and did not require statistical adjustment in the analyses (see Table S3 in the online supplementary material). 


\section{Results}

LCA

A series of latent class models were explored, ranging from two to six latent classes. The AIC, BIC, A-BIC and $p$ values for the LMR likelihood ratio test and vLMR likelihood ratio test indicated that the five-class model was statistically the most feasible model (see Table S4 in the online supplementary material), though a four-class solution might work better if $p$ values of the LMR likelihood ratio test and vLMR likelihood ratio test were set at 0.01 . More importantly, the five-class model provided the most meaningful classifications of lifecourse accumulated adversities and thus was chosen for further analysis. ${ }^{1}$

The model-based (five-class model) predicted probabilities for each of the 16 adversities by latent clusters are presented in Table S1 and illustrated in Figure S1 (both in the online supplementary material). The results show very low probabilities of all adversities in Cluster 1; high probabilities of losing a very close friend/relative at risk of death/died due to illness/serious accident and providing long-term care in Cluster 2; high probabilities of childhood physical abuse, physical violence, sexual violence, natural disaster, life-threatening illness and financial difficulties in Cluster 3; high probabilities of childhood parental unemployment, drink/drug use and frequent fighting in Cluster 4; and high probabilities of having ever witnessed the serious injury/death of someone in war or military action, ever fired a weapon in combat or been fired upon, and ever lost a very close friend/relative in war or military service in Cluster 5.

Thus, the created latent clusters were named as follows:

(1) $\mathrm{No} / \mathrm{few}$ lifecourse adversities (58.6\%).

(2) Relationship lost (27.0\%).

(3) Chained lifecourse adversities (2.4\%).

(4) Childhood adversities (6.3\%).

(5) War-related adversities (5.7\%).

\section{Classification and characteristics of latent clusters}

Table 2 comprises a summary of the descriptive characteristics of the five clusters of the latent variable of accumulated lifecourse adversities. Cluster 1 (no/few lifecourse adversities) represented the largest group of older people (59\%) who had no or few lifecourse adversities. Cluster 2 (relationship lost), as described above, characterised older people who had suffered bereavement and provided long-term informal care. Compared with the other clusters, this group (27\%) shows a significantly higher educational status and social class. Cluster 3 (chained lifecourse adversities) embodied a small group of people (2\%) who experienced multiple chained adversities through life. Compared to the other clusters, this group was relatively younger, female, more likely to be in a lower social class, currently smoking and had a low level of physical activity. Cluster 4 (childhood adversities) shows a group in which a substantial proportion were female and from a relatively lower social class. Cluster 5 (war-related adversities) included significant proportions of individuals who are of older age, male, with a lower education, former smokers and reporting low physical activity. 
Table 2. Cluster characteristics

\begin{tabular}{|c|c|c|c|c|c|c|c|}
\hline & \multicolumn{7}{|c|}{ Lifecourse adversities cluster } \\
\hline & $\begin{array}{c}1 \\
\text { No/few } \\
\text { adversities }\end{array}$ & $\begin{array}{c}2 \\
\text { Relationship } \\
\text { lost }\end{array}$ & $\begin{array}{c}3 \\
\text { Chained } \\
\text { adversities }\end{array}$ & $\begin{array}{c}4 \\
\text { Childhood } \\
\text { adversities }\end{array}$ & $\begin{array}{c}5 \\
\text { War-related } \\
\text { adversities }\end{array}$ & Total & $p$ \\
\hline Percentage of sample & 58.6 & 27.0 & 2.4 & 6.3 & 5.7 & 100 & - \\
\hline \multirow[t]{2}{*}{ Mean age } & 66.2 & 65.9 & 60.6 & 62.9 & 74.2 & 66.3 & 0.000 \\
\hline & \multicolumn{5}{|c|}{ Percentages } & & \\
\hline Female & 57.6 & 55.7 & 71.2 & 65.1 & 11.1 & 55.2 & 0.000 \\
\hline Education: & & & & & & & 0.000 \\
\hline Low ( $\leqslant 14$ years) & 14.5 & 13.5 & 10.4 & 10.1 & 38.9 & 15.2 & \\
\hline Intermediate (15-16 years) & 56.1 & 53.1 & 57.6 & 64.5 & 41.6 & 55.0 & \\
\hline High ( $\geqslant 17$ years) & 29.4 & 33.4 & 32.0 & 25.4 & 19.5 & 29.7 & \\
\hline NS-SEC: & & & & & & & 0.071 \\
\hline $\begin{array}{l}\text { Higher managerial/ } \\
\text { professional }\end{array}$ & 33.5 & 36.6 & 28.8 & 31.8 & 36.9 & 34.3 & \\
\hline Intermediate & 26.6 & 26.2 & 26.4 & 22.6 & 24.2 & 26.2 & \\
\hline Routine/manual & 38.7 & 35.8 & 44.0 & 45.3 & 38.6 & 38.5 & \\
\hline Long-term unemployed & 1.1 & 1.4 & 0.8 & 0.3 & 0.3 & 1.1 & \\
\hline Smoking status: & & & & & & & 0.000 \\
\hline Never smoked & 42.7 & 37.9 & 36.0 & 35.2 & 24.8 & 39.7 & \\
\hline Current smoker & 11.2 & 14.0 & 23.2 & 19.6 & 12.8 & 12.9 & \\
\hline Former smoker & 46.1 & 48.1 & 40.8 & 45.3 & 62.4 & 47.4 & \\
\hline
\end{tabular}




\begin{tabular}{|c|c|c|c|c|c|c|c|}
\hline & \multicolumn{7}{|c|}{ Lifecourse adversities cluster } \\
\hline & $\begin{array}{c}1 \\
\text { No/few } \\
\text { adversities }\end{array}$ & $\begin{array}{l}2 \\
\text { Relationship } \\
\text { lost }\end{array}$ & $\begin{array}{c}3 \\
\text { Chained } \\
\text { adversities }\end{array}$ & $\begin{array}{c}4 \\
\text { Childhood } \\
\text { adversities }\end{array}$ & $\begin{array}{c}5 \\
\text { War-related } \\
\text { adversities }\end{array}$ & Total & $p$ \\
\hline Drinking status: & & & & & & & 0.021 \\
\hline$<$ Daily & 15.5 & 17.1 & 8.0 & 12.2 & 18.1 & 15.7 & \\
\hline Daily & 75.4 & 74.1 & 77.6 & 79.5 & 70.5 & 75.1 & \\
\hline Missing value & 9.1 & 8.8 & 14.4 & 8.3 & 11.4 & 9.2 & \\
\hline Physical activity: & & & & & & & 0.009 \\
\hline Low & 27.7 & 30.0 & 37.6 & 28.4 & 35.9 & 29.0 & \\
\hline Moderate & 52.4 & 50.3 & 47.2 & 46.8 & 46.0 & 51.0 & \\
\hline $\mathrm{N}$ & 3,044 & 1,404 & 125 & 327 & 298 & 5,198 & \\
\hline
\end{tabular}

Notes: $\mathrm{N}=5,198 . \mathrm{NS}-\mathrm{SEC}$ : National Statistics Socio-economic Classification.

Source: Authors' analysis of the English Longitudinal Study of Ageing, Wave 3 (2006). 


\section{The association of cumulative major life adversities and depressive symptoms}

Table 1 shows the bivariate association between current depressive symptoms and a range of covariates, including the latent variable of accumulated lifecourse adversities. Overall, 13.0 per cent of the respondents reported depressive symptoms. Lifecourse adversities were associated with depressive symptoms, with the highest prevalence of depressive symptoms being observed among older people in Cluster 3 (chained adversities), followed by Cluster 4 (childhood adversities) and Cluster 2 (relationship lost). Older people in Cluster 1 (no/few adversities) and Cluster 5 (war-related adversities) exhibited relatively lower prevalence of depression. In addition, being female, reporting poor childhood health, being divorced or widowed, having lower education, lower occupational class, lower household wealth, experience of smoking, frequently drinking, reporting less physical activity and higher levels of social isolation were all found to be associated with depressive symptoms. A higher prevalence of current depressive symptoms was found amongst the younger old (50-59) and oldest old (80 and above) age groups.

\section{Current depressive symptoms}

The multivariate logistic regression results (Table 3) show that older people who experienced lifecourse adversities had higher odds of depressive symptoms, even after controlling for selected socio-demographic, health-risk behaviour and social support variables. Specifically, compared with older people who had no/few lifecourse adversities, those who experienced chained adversities had the highest chance of also experiencing depression, followed by those who experienced childhood adversities and those who suffered a lost relationship. Other factors which significantly predict depression included poor childhood self-rated health, lower housing wealth, smoking experience, lower physical activity and a higher level of social isolation. Gender is also significant, as is age, with being young and female both associated with higher odds of experiencing depressive symptoms. The separate models by gender show similar patterns, although interestingly among older men, only one group - those with childhood adversities - had significantly higher odds of experiencing depression; while among older women, having experienced childhood adversities, a lost relationship, war-related adversities and chained adversities all led to higher odds of experiencing depressive symptoms.

\section{New case of depressive symptoms}

Over the follow-up period of eight years (2006-2014), there were 743 new cases of significant depressive symptoms out of 4,041 participants; an incident rate of 18.4 per cent. Figure 2 presents the Kaplan-Meier survival curves for the length of survival time after baseline (2006) until the occurrence of the significant depressive symptoms for men and women separately. The $y$-axis denotes the percentage of the sample who remain with no significant depressive symptoms, while the $x$-axis denotes observed time. Three points stood out. Firstly, among all older respondents who did not have any significant depressive symptoms at baseline, those with no or few major life adversities were more likely to continue in that situation (i.e. having a higher survival rate) than those who experienced chained 
Table 3. Odds ratios (OR) of depressive symptoms

\begin{tabular}{|c|c|c|c|c|c|c|}
\hline \multirow[b]{2}{*}{ Variables and categories } & \multicolumn{2}{|c|}{ Total } & \multicolumn{2}{|c|}{ Male } & \multicolumn{2}{|c|}{ Female } \\
\hline & OR & $p$ & OR & $p$ & OR & $p$ \\
\hline \multicolumn{7}{|l|}{ Lifecourse adversities: } \\
\hline \multicolumn{7}{|l|}{ No/few adversities } \\
\hline Relationship lost & 1.98 & $\star \star \star$ & 1.49 & & 2.29 & $\star \star$ \\
\hline Chained adversities & 4.86 & $\star \star \star$ & 1.75 & & 3.61 & $\star \star \star$ \\
\hline Childhood adversities & 2.08 & $\star \star$ & 2.68 & $\star \star \star$ & 2.13 & $\star \star$ \\
\hline War-related adversities & 1.48 & & 0.41 & & 2.95 & $\star \star \star$ \\
\hline \multicolumn{7}{|l|}{ Age group: } \\
\hline \multicolumn{7}{|l|}{$50-59$} \\
\hline $60-69$ & 0.72 & $\star \star$ & 0.86 & & 0.65 & $\star \star$ \\
\hline $70-79$ & 0.65 & $\star \star$ & 0.87 & & 0.57 & $\star \star \star$ \\
\hline $80+$ & 0.55 & $\star \star \star$ & 0.93 & & 0.45 & $\star \star \star$ \\
\hline \multicolumn{7}{|l|}{ Sex: } \\
\hline \multicolumn{7}{|l|}{ Male } \\
\hline Female & 1.28 & * & & & & \\
\hline \multicolumn{7}{|l|}{ Current marital status: } \\
\hline \multicolumn{7}{|l|}{ Never married } \\
\hline First marriage & 0.86 & & 0.80 & & 0.89 & \\
\hline Remarried & 0.63 & * & 0.51 & * & 0.73 & \\
\hline Divorced & 1.34 & & 1.31 & & 1.38 & \\
\hline Widowed & 1.69 & & 1.65 & & 1.73 & \\
\hline \multicolumn{7}{|l|}{ Childhood self-rated health: } \\
\hline \multicolumn{7}{|l|}{ Good } \\
\hline Fair/poor & 1.58 & $\star \star$ & 2.11 & $\star \star$ & 1.42 & $\star \star \star$ \\
\hline ADL difficulties & 1.45 & $\star \star *$ & 1.56 & $\star \star \star$ & 1.42 & $\star \star \star *$ \\
\hline \multicolumn{7}{|l|}{ Education: } \\
\hline \multicolumn{7}{|l|}{ Low ( $\leqslant 14$ years) } \\
\hline Intermediate (15-16 years) & 1.08 & & 1.53 & & 0.90 & \\
\hline High ( $\geqslant 17$ years) & 0.84 & & 1.05 & & 0.78 & \\
\hline \multicolumn{7}{|l|}{ NS-SEC: } \\
\hline \multicolumn{7}{|c|}{ Higher managerial/professional } \\
\hline Intermediate & 1.18 & & 1.17 & & 1.21 & \\
\hline Routine/manual & 1.27 & & 1.23 & & 1.34 & \\
\hline Long-term unemployed & 0.81 & & 1.38 & & 0.72 & \\
\hline
\end{tabular}


Table 3. (Continued.)

\begin{tabular}{|c|c|c|c|c|c|c|}
\hline \multirow[b]{2}{*}{ Variables and categories } & \multicolumn{2}{|c|}{ Total } & \multicolumn{2}{|c|}{ Male } & \multicolumn{2}{|c|}{ Female } \\
\hline & OR & $p$ & OR & $p$ & OR & $p$ \\
\hline \multicolumn{7}{|l|}{ Housing wealth $(£)$ : } \\
\hline \multicolumn{7}{|l|}{ None } \\
\hline $1-149,999$ & 0.64 & $\star \star \star$ & 0.63 & $\star \star$ & 0.64 & $\star \star \star$ \\
\hline $150,000-299,999$ & 0.56 & $\star \star \star$ & 0.62 & $\star \star$ & 0.52 & $\star \star \star$ \\
\hline $300,000-449,999$ & 0.58 & $\star \star \star$ & 0.61 & * & 0.53 & $\star \star \star$ \\
\hline $450,000+$ & 0.30 & $\star \star \star *$ & 0.30 & $\star \star \star$ & 0.27 & $\star \star \star$ \\
\hline \multicolumn{7}{|l|}{ Smoking status: } \\
\hline \multicolumn{7}{|l|}{ Never smoker } \\
\hline Currently smoker & 1.34 & & 1.06 & & 1.44 & \\
\hline Former smoker & 1.04 & & 0.78 & & 1.18 & \\
\hline \multicolumn{7}{|l|}{ Drinking status: } \\
\hline \multicolumn{7}{|l|}{$<$ Daily } \\
\hline Daily & 1.13 & & 1.76 & & 0.82 & \\
\hline Missing & 1.78 & * & 3.19 & * & 1.20 & \\
\hline \multicolumn{7}{|l|}{ Physical activity: } \\
\hline \multicolumn{7}{|l|}{ Low } \\
\hline Moderate & 0.68 & $\star \star \star$ & 0.62 & $\star \star$ & 0.68 & $\star \star$ \\
\hline High & 0.54 & 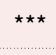 & 0.57 & $\star \star$ & 0.48 & $\star \star \star$ \\
\hline \multicolumn{7}{|l|}{ Work status: } \\
\hline \multicolumn{7}{|l|}{ Not retired } \\
\hline Retired & 0.99 & & 0.93 & & 1.04 & \\
\hline \multicolumn{7}{|l|}{ Social isolation: } \\
\hline \multicolumn{7}{|l|}{ Low } \\
\hline Median & 1.12 & & 1.07 & & 1.09 & \\
\hline High & 1.83 & $\star *$ & 2.44 & * & 1.56 & \\
\hline Missing & 1.37 & & 1.35 & & 1.38 & \\
\hline
\end{tabular}

Notes: $N=5,198$. ADL: activity of daily living. NS-SEC: National Statistics Socio-economic Classification. Source: Authors' analysis of the English Longitudinal Study of Ageing, Wave 3 (2006). Significance levels: ${ }^{\star} p<0.05,{ }^{\star *} p<0.01,{ }^{\star \star \star} p<0.001$.

adversities, childhood adversities, war-related adversities and relationship loss. Secondly, compared to male elders, most female elders faced a higher risk of the onset of depression, with lower survival curves than men. Finally, men who experienced chained adversities faced the highest risk of the onset of depression, while women who experienced war-related adversities had the highest risk. 


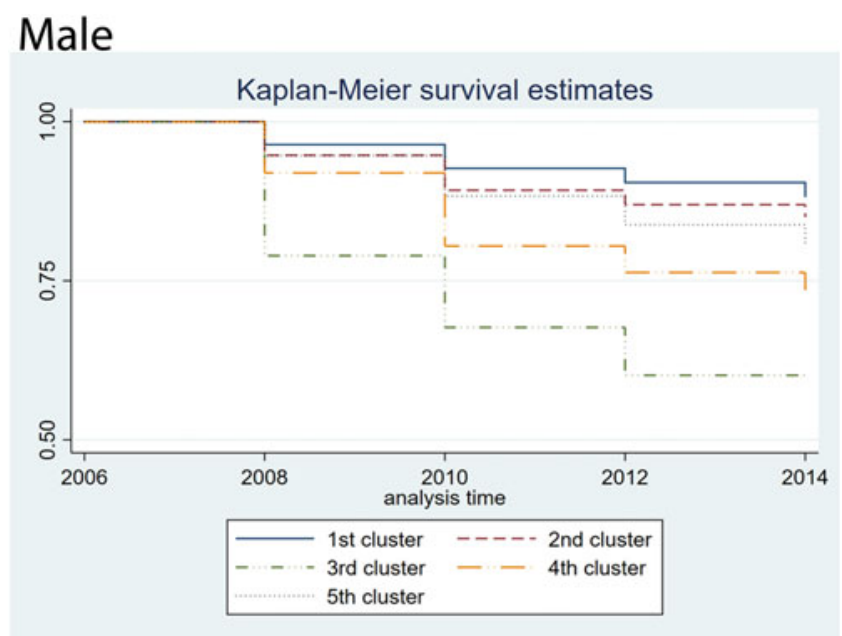

\section{Female}

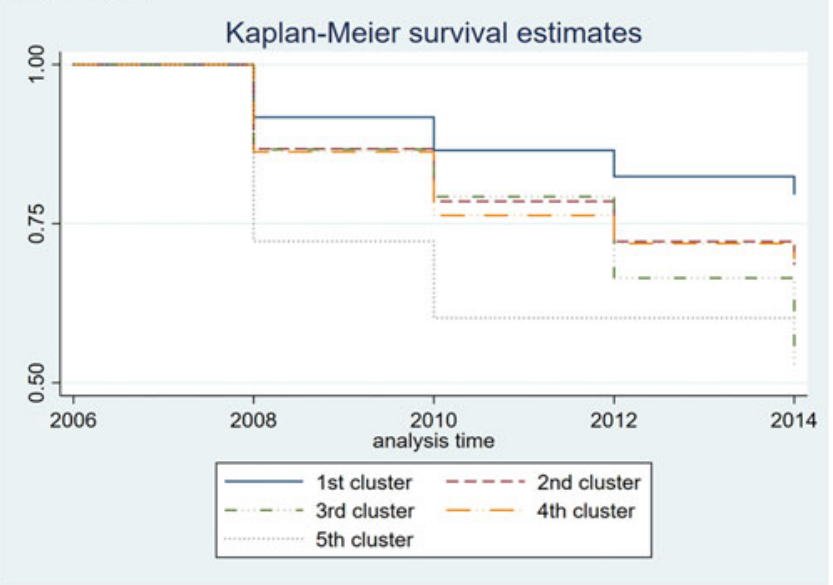

Figure 2. Kaplan-Meier survival estimates for the length of survival time after baseline (2006) until the occurrence of significant depressive symptoms for men and women.

Notes: The $y$-axis denotes the percentage of the sample who remain with no significant depressive symptoms. 1st cluster: no/few adversaries; 2nd cluster: relationship lost; 3rd cluster: chained adversities; 4th cluster: childhood adversities; 5th cluster: war-related adversities.

Source: Authors' analysis of the English Longitudinal Study of Ageing, Waves 3 (2006), 4 (2008), 5 (2010), 6 (2012) and 7 (2014).

Table 4 shows that participants who experienced childhood adversities, a lost relationship and war-related adversities over the lifecourse had a higher hazard ratio (HR) of developing depressive symptoms, even after controlling for sociodemographic, health behaviour and social support variables. Older women were more likely $(\mathrm{HR}=1.67)$ to develop depressive symptoms during the eight-year follow-up period than their male counterparts. Other factors which significantly 
Table 4. Hazard ratios (HR) of depressive symptoms

\begin{tabular}{|c|c|c|c|c|c|c|}
\hline \multirow[b]{2}{*}{ Variables and categories } & \multicolumn{2}{|c|}{ Total } & \multicolumn{2}{|c|}{ Male } & \multicolumn{2}{|c|}{ Female } \\
\hline & HR & $p$ & HR & $p$ & $\mathrm{HR}$ & $p$ \\
\hline \multicolumn{7}{|l|}{ Lifecourse adversities: } \\
\hline \multicolumn{7}{|l|}{ No/few adversities } \\
\hline Relationship lost & 1.89 & $\star \star \star$ & 1.37 & & 2.25 & $\star \star \star$ \\
\hline Chained adversities & 1.31 & & 0.94 & & 2.91 & $\star \star \star$ \\
\hline Childhood adversities & 2.35 & $\star \star \star$ & 2.87 & $\star \star \star$ & 1.97 & $\star \star \star$ \\
\hline War-related adversities & 1.75 & * & 1.49 & & 1.79 & $\star \star$ \\
\hline \multicolumn{7}{|l|}{ Age at baseline (Ref. 50-59) } \\
\hline $60-69$ & 1.07 & & 1.02 & & 1.13 & \\
\hline $70-79$ & 1.11 & & 0.92 & & 1.27 & \\
\hline $80+$ & 1.52 & * & 1.60 & & 1.50 & * \\
\hline \multicolumn{7}{|l|}{ Sex (Ref. Male): } \\
\hline Female & 1.76 & $\star \star \star$ & & & & \\
\hline \multicolumn{7}{|l|}{$\begin{array}{l}\text { Marital status at baseline (Ref. Never } \\
\text { married) }\end{array}$} \\
\hline First marriage & 1.03 & & 0.93 & & 1.06 & \\
\hline Remarried & 1.17 & & 1.14 & & 1.13 & \\
\hline Divorced & 1.01 & & 1.05 & & 1.01 & \\
\hline Widowed & 0.99 & & 0.89 & & 1.01 & \\
\hline \multicolumn{7}{|l|}{ Childhood self-rated health (Ref. Good): } \\
\hline Fair/poor & 1.15 & & 1.65 & $\star \star$ & 0.95 & \\
\hline ADL difficulties (continuous variable) & 1.23 & $\star \star \star$ & 1.27 & ** & 1.23 & $\star \star \star$ \\
\hline \multicolumn{7}{|l|}{ Education (Ref. Low ( $\leqslant 14$ years)): } \\
\hline Intermediate (15-16 years) & 0.85 & & 0.77 & & 0.86 & \\
\hline High ( $\geqslant 17$ years) & 0.78 & * & 0.91 & & 0.69 & * \\
\hline \multicolumn{7}{|l|}{$\begin{array}{l}\text { NS-SEC (Ref. Higher managerial/ } \\
\text { professional: }\end{array}$} \\
\hline Intermediate & 1.01 & & 0.81 & & 1.12 & \\
\hline Routine/manual & 0.97 & & 0.80 & & 1.05 & \\
\hline Long-term unemployed & 1.00 & & 0.72 & & 1.09 & \\
\hline \multicolumn{7}{|l|}{ Housing wealth (£; Ref. None) } \\
\hline $1-149,999$ & 0.95 & & 0.79 & & 1.04 & \\
\hline $150,000-299,999$ & 0.85 & & 0.74 & & 0.91 & \\
\hline $300,000-449,999$ & 0.69 & * & 0.55 & * & 0.74 & \\
\hline
\end{tabular}


Table 4. (Continued.)

\begin{tabular}{|c|c|c|c|c|c|c|}
\hline \multirow[b]{2}{*}{ Variables and categories } & \multicolumn{2}{|c|}{ Total } & \multicolumn{2}{|c|}{ Male } & \multicolumn{2}{|c|}{ Female } \\
\hline & $\mathrm{HR}$ & $p$ & $\mathrm{HR}$ & $p$ & HR & $p$ \\
\hline $450,000+$ & 0.68 & * & 0.58 & & 0.70 & \\
\hline \multicolumn{7}{|c|}{ Smoking status (Ref. Never smoked): } \\
\hline Current smoker & 1.24 & & 1.44 & & 1.14 & \\
\hline Former smoker & 1.07 & & 1.11 & & 1.06 & \\
\hline \multicolumn{7}{|l|}{ Drinking status (Ref. < Daily): } \\
\hline Daily & 1.13 & & 1.50 & * & 0.93 & \\
\hline Missing & 0.98 & * & 1.22 & & 0.84 & \\
\hline \multicolumn{7}{|l|}{ Physical activity (Ref. Low): } \\
\hline Moderate & 0.69 & $\star \star \star$ & 0.56 & $\star \star \star$ & 0.76 & $\star \star$ \\
\hline High & 0.70 & $\star \star$ & 0.67 & * & 0.72 & * \\
\hline Work status (Ref. Not retired) & 1.04 & & 1.21 & & 0.97 & \\
\hline \multicolumn{7}{|l|}{ Social isolation (Ref. Low): } \\
\hline Median & 1.18 & & 0.96 & & 1.26 & \\
\hline High & 1.05 & & 1.02 & & 1.09 & \\
\hline Missing & 1.22 & & 1.50 & $\star$ & 1.10 & \\
\hline
\end{tabular}

Notes: $\mathrm{N}$ in Wave $3=4,041$ (1,861 males and 2,180 females). Ref.: reference category. ADL: activity of daily living. NS-SEC: National Statistics Socio-economic Classification.

Source: Authors' analysis of the English Longitudinal Study of Ageing, Waves 3 (2006), 4 (2008), 5 (2010), 6 (2012) and 7 (2014).

Significance levels: ${ }^{\star} p<0.05,{ }^{\star \star} p<0.01,{ }^{\star \star \star} p<0.001$.

influence the likelihood of experiencing a new case of depressive symptoms included lower educational status and low levels of physical activity.

The separate Cox regression models show somewhat different results. For men, only those who experienced childhood adversities had a significantly higher HR for the onset of significant depressive symptoms; while among women, in addition, those who suffered a lost relationship, chained adversities and war-related adversities also had a higher risk of experiencing depressive symptoms. Moreover, higher education was a protective factor for depression among women and relatively better housing wealth was a protective factor for depression among men, while daily drinking and poor childhood health were risk factors for men. ${ }^{2}$

\section{Discussion}

This study characterised a typology of accumulated lifecourse adversities based on LCA and investigated the associations between types of adversities and mental health in later life. The findings address important aspects of lifecourse research by adopting a comprehensive approach which described one's entire lifecourse adversity experience (Pietrzak and Cook, 2013), and considered conditions at 
earlier stages of the lifecourse in order to explain mental health in later life (Pearlin et al., 2005; Ferraro and Shippee, 2009).

The results of this study suggest that five clustered major adversities experiences emerged over the lifecourse among older people and the corresponding sociodemographic correlates were not distributed randomly for these clusters. Older people with chained adversities and those with childhood adversities were more likely to be women and in relative disadvantage in terms of social conditions; while groups with war-related adversities were dominated more by men and relatively older persons. The social differences of adversity exposure were consistent with a previous study (Kessler et al., 2017). Compared to the conventional measurement of major adversities, i.e. simple counts of the total number of adversities or in one particular life period, e.g. childhood adversity, the LCA provided a more holistic and detailed compositional dimension of exposure to adversity over one's entire lifecourse.

The findings further suggest that cumulative major life adversities were associated with both the prevalence and incidence of depressive symptoms among older-age people in England. Broadly consistent with existing research (Shrira, 2012, 2014), those who had experienced childhood adversities (odds ratio (OR) $=2.08, \mathrm{HR}=2.35)$ and a lost relationship $(\mathrm{OR}=1.98, \mathrm{HR}=1.89)$ faced a higher risk of having poor mental health outcomes in later life, even after controlling for socio-demographic characteristics, health-risk behaviours and social support. These findings support our hypotheses that the risk of suffering depressive symptoms in later life was higher amongst those who have suffered accumulated lifecourse adversities than those who have not. In addition, this effect persists into later life. Interestingly, chained adversity was only associated with the prevalence of depression $(\mathrm{OR}=4.86)$, while war-related adversity was only significantly associated with the incidence of depression $(\mathrm{HR}=1.75)$. The possible explanation might be that respondents who have experienced chained adversity had a very high chance of earlier onset of depression ( $\mathrm{OR}=4.86$ ), and among this sub-group, those clear of depression for the longitudinal analysis may have much better resilience than other sub-groups. Future studies in this area would require more information about the respondents' stress coping resources and strategies in response to lifecourse adversities. In addition, war-related adversities might be linked with an advanced age at the onset of depression. Indeed, a previous study found that most veterans aged 60 and above were psychologically resilient (Pietrzak and Cook, 2013), while another study indicated mental health vulnerability among very old (aged 75 and above) Holocaust survivors (Landau and Litwin, 2000).

Older women experienced higher odds of depressive symptoms and a higher hazard of reporting new symptoms over an eight-year follow-up period. Cumulative major life adversities were positively associated with depressive symptoms among both older men and women. However, more identified latent clusters of accumulated lifecourse adversities among women were significantly associated with both the prevalence and incidence of depression in later life. These findings were in line with the assumption that women's mental health in later life was more sensitive to earlier life adversities than men's. A number of factors can be put forward to explain these gender differences, including differences in the experience of adverse events themselves, as well as in biological responses to stress, 
mediated through the gendered nature of social roles (Nazroo et al., 1997; Taylor et al., 2000; Lundberg, 2005). Notwithstanding the increase in women undertaking paid work roles alongside their caring obligations, nevertheless women's relative lack of social power may mean that women are more likely to encounter certain stressors, such as sexual assault, more often than men; this same lack of social power may then make them more vulnerable to developing depression in response to stress (Nolen-Hoeksema, 2001; see also Table S2 in the online supplementary material). These results are in line with previous research findings that women were more vulnerable than men to developing depression and anxiety disorders, such as post-traumatic stress disorder, even when they were threatened with similar stressors (Breslau et al., 1997).

Taken together, the findings in this study emphasise the long-term consequences of lifecourse adversities on mental health in later life, as well as the gender differences permeating such relationships. The study identifies a five-categorical taxonomy of lifecourse adversities, namely the experience of a lost relationship, chained adversities, childhood adversities, war-related adversities and no/few adversities. Several types of early life exposures in childhood and early adulthood still operated as risk factors of late-onset depression, and there existed gender differences within such relationships. Lifecourse adversity exposures may create a vulnerable stress regulation system which continues into old age, and the nature of such vulnerability is likely to be specific to certain patterns of exposure. Our study has several strengths, including a large study sample, detailed life-history data and the use of LCA with distal outcomes. However, our findings should be assessed in the light of the study limitations. The measurement of lifetime adversity was based on retrospective data, raising the prospect that the relationship between adversity and depression may be over- or under-estimated due to selective recall of these events as a function of current depression (Hardt and Rutter, 2004). Such recall bias was partially mitigated here, in that the reports of lifetime adversity at baseline (2006) were made at a different time-point to the reports of depressive symptoms during the follow-up period (2008-2014). Additionally, it was unclear from the data whether the current episode of depressive symptoms reflects the first onset or reoccurrence of these symptoms, and in both the logistic regression and Cox regression analysis we could only establish the association between the lifecourse adversities and the first onset or recurrence of depression. However, a previous study found that a gender difference (with women at an increased risk) was revealed for the first onset of depression only (Wainwright and Surtees, 2002), providing some support to the gender differentials found here being indicative of a first onset. Thirdly, it is important to recognise that other recent, unobserved, life events might also influence the outcome, although previous research has found that the effect of recent life events on depressive symptoms may be weaker and time limited (Kraaij et al., 2002). Finally, the very small class of 'chained adversities' (2.4\%) might be associated with considerable uncertainty and classification error, pointing to the need for further research to explore the existence of this sub-group in other settings.

Notwithstanding these limitations, this study contributes to the literature on the link between clustered cumulative life adversities, and current and new depressive symptoms. Understanding this association is important not only in its own right, 
but also because poor mental health has been associated with an increased risk of morbidity and mortality in later life in various contexts, with depression being a particularly strong predictor of mortality in relation to cardiac failure and stroke (House et al., 2001; Pennix et al., 2001). An elevated risk of depressive symptoms in later life is often associated with normative events as part of the process of ageing, such as retirement, widowhood and reduced ability to perform ADLs. Acknowledging that the current picture may be further complicated by the longer term and cumulative impact of early life adversities can help inform the design of future preventive interventions and treatments, and improve both current and future mental health among individuals.

\section{Policy and practice implications}

The paper's findings have important implications for the general population and the practice of health and social care professionals. The significant associations between early life adversities and the onset and prevalence of depression in old age indicate a need to create broader public awareness and understanding about the effects of harmful stress from different types of adverse lifecourse experiences on mental health across a wider population. Depression affects about 22 and 28 per cent of men and women over 65, respectively (Health Survey for England, 2007), however previous research shows that fewer than one in six older people with depression discuss their symptoms with their general practitioner, and among those, only half receive adequate treatment (Chew Graham et al., 2011). In addition, NHS England's National Director for Older People's Mental Health has highlighted that older people are a fifth as likely as younger age groups to have access to talking therapies but six times as likely to be on medication (Burns, 2015). Developing mechanisms to encourage older people to share their lifecourse experiences and symptoms of depression can effectively contribute to treating depression and promoting better mental health among the older population. The findings in this paper also relate to the UK government's recent efforts to raise awareness about social isolation and its link to, among a range of other factors, depression across the lifecourse and in later life (HM Government, 2018). Acknowledging the significant impact of lifecourse adversities on older men's and women's risk of developing depression, and by extension their risk of living in social isolation, is an important step in preventing and treating the negative effects associated with adverse mental health for individuals across socio-economic strata and with diverse demographic characteristics.

\section{Future research}

For future research, it would be interesting to add the precise timing dimension of these events within one's lifecourse into the LCA. Lifecourse adversity may have a different impact depending on when and how adversities occur. Also, it would be ideal to lag the timing of depressive symptom onset in the multivariate analyses in order to allow for the control of prior conditions, especially the first onset of depression. Lastly, it could be important to repeat the analyses in other contexts including other European countries, the United States of America and China, 
where the similarly designed and structured survey data (the Survey of Health, Ageing and Retirement in Europe, the Health and Retirement Study, and China Health and Retirement Longitudinal Study) are available.

\section{NOTES}

1 It was noticed that the third sub-group of chained lifecourse adversities had a small sample size (2.4\%). Given this it was felt to be important to explore differences between the five-class solution and four-class solution. The category of chained lifecourse adversities in the five-class solution was nearly all combined with that of childhood adversities in the four-class solution, whilst the other three types remained largely unchanged. The class counts (proportions) for the four classes of no/few chances of adversities, relationship lost, childhood adversities and war-related adversities were 3,408 (65.6\%), 1,068 (20.5\%), $436(8.4 \%)$ and 286 (5.5\%), respectively. Although the four-class solution increased the sample size of the sub-group of childhood adversities, some relatively high-probability events experienced by the sub-group of chained lifecourse adversities also became part of the feature of the sub-group of childhood adversities, e.g. ever been a victim of sexual assault (including rape or harassment), ever been a victim of serious physical attack or assault, ever had a husband/wife/partner/child who has been addicted to drugs or alcohol, and ever experienced severe financial hardship (data not shown). Given that we felt it important to distinguish the small group of people featured with chained adversities from those who only suffered from childhood adversities, the five-class solution was chosen.

2 We also ran multivariate models (both logistic regression and Cox regression) using the four-class solution and compared the results from the two solutions. The odds ratio (data not shown) of the respondents with childhood adversities versus those with no/few chances of adversities were slightly higher using the four-class solution than that of using the five-class solution, reflecting the fact that in the four-class solution, this sub-group of people also suffered from the chained lifecourse adversities which were very harmful to their mental health. Both were statistically significant, with $p<0.01$ in the five-class solution model and $p<0.001$ in the four-solution model. We did the same comparisons for the hazard ratios and found they were similar in terms of the value of the hazard ratios and the statistical significance (data not shown).

Supplementary material. The supplementary material for this article can be found at https://doi.org/10. 1017/S0144686X19000461.

Author ORCIDs. (D) Jane Falkingham, 0000-0002-7135-5875; Athina Vlachantoni, 0000-0003-1539-3057.

Financial support. This work was supported by the Economic and Social Research Council Centre for Population Change (grant number ES/K007394/1 at the University of Southampton).

Conflict of interest. The authors declare no conflicts of interest.

Ethical standards. Ethics approval was not required for this project as the data from the English Longitudinal Study of Ageing were anonymised at the sources by the survey team.

\section{References}

Ahern K and Brocque RL (2005) Methodological issues in the effects of attrition: simple solutions for social scientists. Field Methods 17, 53-69.

Asparouhov T and Muthén BO (2014) Auxiliary variables in mixture modeling: three-step approaches using Mplus. Structural Equation Modeling: A Multidisciplinary Journal 21, 329-341.

Banks J, Muriel A and Smith JP (2011) Attrition and health in ageing studies: evidence from ELSA and HRS. Longitudinal and Life Course Studies 2, 1-29.

Blazer D (2003) Depression in late life: review and commentary. Journals of Gerontology: Medical Sciences 58A, 249-265.

Breslau N, Davis GC, Andreski P, Peterson EL and Schultz L (1997) Sex differences in posttraumatic stress disorder. Archives of General Psychiatry 54, 1044-1048. 
Briere J and Elliot D (2000) Prevalence, characteristics, and long-term sequelae of natural disaster exposure in the general population. Journal of Traumatic Stress 13, 661-679.

Burns A (2015) Better Access to Mental Health Services for Older People. Available at https://www.england. nhs.uk/blog/mh-better-access/.

Chen E, Turiano NA, Mroczek DK and Miller GE (2016) Association of reports of childhood abuse and all-cause mortality rates in women. JAMA Psychiatry 73, 920-927.

Chew Graham C, Campion J, Kaiser P and Edwards K (2011) Managing of Depression in Older People: Why This is Important in Primary Care. Forum for Mental Health in Primary Care. http://www.rcgp.org. uk/mental_health.aspx.

Ferraro KF and Shippee TP (2009) Aging and cumulative inequality: how does inequality get under the skin? The Gerontologist 49, 333-343.

Fiske A, Gatz M and Pedersen NL (2003) Depressive symptoms and aging: the effects of illness and nonhealth related events. Journals of Gerontology: Psychological Sciences 58B, 320-328.

Friedman EM, Karlamangla AS, Gruenewald T, Koretz B and Seeman TE (2015) Early life adversity and adult biological risk profiles. Psychosomatic Medicine 77, 176-185.

Goodman LA (2002) Latent class analysis: the empirical study of latent types, latent variables, and latent structures. In Hagenaars JA and McCutcheon AL (eds), Applied Latent Class Analysis. Cambridge: Cambridge University Press, pp. 3-55.

Green BL, Goodman LA, Krupnick JL, Corcoran BL, Petty RM, Stockton P and Stern NM (2000) Outcomes of single versus multiple trauma exposure in a screening sample. Journal of Traumatic Stress 13, 271-286.

Hardt J and Rutter M (2004) Validity of adult retrospective reports of adverse childhood experiences: review of the evidence. Journal of Child Psychology and Psychiatry 45, 260-273.

Health Survey for England (2007) Health Survey for England, 2005: Health of Older People. Available at https://digital.nhs.uk/data-and-information/publications/statistical/health-survey-for-england/.

HM Government (2018) A Connected Society - A Strategy for Tackling Loneliness - Laying the Foundations for Change. London: Department for Digital, Media, Culture and Sport.

Horwitz AV, Widom CS, McLaughlin J and White HR (2001) The impact of childhood abuse and neglect on adult mental health: a prospective study. Journal of Health and Social Behavior 42, 184-201.

House A, Knapp P, Bamford J and Vali A (2001) Mortality at 12 and 24 months after stroke may be associated with depressive symptoms at 1 month. Stroke 32, 696-701.

Karim J, Weisz R, Bibi Z and Rehman S (2015) Validation of the Eight-Item Center for Epidemiologic Studies Depression Scale (CES-D) among older adults. Current Psychology 34, 681-692.

Kessler RC, Aguilar-Gaxiola S, Alonso J, Benjet C, Bromet EJ, Cardoso G, Degenhardt L, Girolamo G, Dinolova RV, Ferry F, Florescu S, Gureje O, Haro JM, Huang Y, Karam EG, Kawakami N, Lee S, Lepine JP, Levinson D, Navarro-Mateu F, Pennell B, Piazza M, Posada-Villa J, Scott KM, Stein DJ, Have MT, Torres Y, Viana MC, Petukhova MV, Sampson NA, Zaslavsky AM and Koenen KC on behalf of the WHO World Mental Health Survey Collaborators (2017) Trauma and PTSD in the WHO World Mental Health Surveys. European Journal of Psychotraumatology 8, 1353383.

Kessler RC, Nelson CB, McGonagle KA, Liu J, Swartz M and Blazer DG (1996) Comorbidity of DSM-III-R major depressive disorder in the general population: results from the US National Comorbidity Survey. British Journal of Psychiatry 168, 17-30.

Kraaij V, Arensman E and Spinhoven P (2002) Negative life events and depression in elderly persons: a meta-analysis. Journals of Gerontology: Psychological Sciences 57B, 87-94.

Landau R and Litwin $\mathbf{H}$ (2000) The effects of extreme early stress in very old age. Journal of Traumatic Stress 13, 473-487.

Lundberg U (2005) Stress hormones in health and illness: the roles of work and gender. Psychoneuroendocrinology 30, 1017-1021.

Marmot M, Oldfield Z, Clemens S, Blake M, Phelps A, Nazroo J, Steptoe A, Rogers N, Banks J and Oskala A (2016) English Longitudinal Study of Ageing: Waves 0-7, 1998-2015 (Data collection), 26th Edn. UK Data Service. SN: 5050.

McEwen BS (1998) Protective and damaging effects of stress mediators. New England Journal of Medicine 338, 171-179. 
McManus S, Bebbington P, Jenkins R and Brugha T (eds) (2016) Mental Health and Wellbeing in England: Adult Psychiatric Morbidity Survey 2014. Leeds, UK: NHS Digital.

Muthén LK and Muthén BO (2017) Mplus User's Guide, 8th Edn. Los Angeles, CA: Muthén \& Muthén.

Nazroo JY, Edwards AC and Brown GW (1997) Gender differences in the onset of depression following a shared life event: a study of couples. Psychological Medicine 27, 9-19.

Nolen-Hoeksema S (2001) Gender differences in depression. Current Directions in Psychological Science 10, 173-176.

Nurius PS, Green S, Logan-Greene P and Borja S (2015) Life course pathways of adverse childhood experiences toward adult psychological well-being: a stress process analysis. Child Abuse and Neglect 45, 143-153.

Nusslock R and Miller GE (2016) Early-life adversity and physical and emotional health across the lifespan: a neuroimmune network hypothesis. Society of Biological Psychiatry 80, 23-32.

Office for National Statistics (ONS) (2015) National Population Projections: 2014-based Statistical Bulletin. Available at https://www.ons.gov.uk/peoplepopulationandcommunity/populationandmigration/ populationprojections/bulletins/nationalpopulationprojections/2015-10-29-older-people.

Office for National Statistics (ONS) (2017) Population Estimates for UK, England and Wales, Scotland and Northern Ireland: Mid-2016. Available at https://www.ons.gov.uk/peoplepopulationandcommunity/ populationandmigration/populationestimates/bulletins/annualmidyearpopulationestimates/mid2016.

O'Rand AM and Hamil-Luker J (2005) Processes of cumulative adversity: childhood disadvantage and increased risk of heart attack across the life course. Journals of Gerontology: Psychological Sciences and Social Sciences 60B, 117-124.

Palgi Y, Shrira A, Ben-Ezra M, Shiovitz-Ezra S and Ayalon L (2012) Self- and other-oriented potential lifetime traumatic events as predictors of loneliness in the second half of life. Aging \& Mental Health 16, 423-430.

Pearlin LI, Schieman S, Fazio EM and Meersman SC (2005) Stress, health, and the life course: some conceptual perspectives. Journal of Health and Social Behavior 46, 205-219.

Pennix B, Geerlings S, Deeg D, van Eijk J, van Tilling W and Beekman A (2001) Minor and major depression and the risk of death in older persons. Archives of General Psychiatry 56, 889-895.

Pietrzak RH and Cook JM (2013) Psychological resilience in older U.S. Veterans: results from the national health and resilience in veterans study. Depression and Anxiety 30, 432-443.

Pirkola S, Isometsä E, Aro H, Kestilä L, Hämäläinen J, Veijola J, Kiviruusu O and Lönnqvist J (2005) Childhood adversities as risk factors for adult mental disorders. Social Psychiatry and Psychiatric Epidemiology 40, 769-777.

Pitzer LM and Fingerman KL (2010) Psychosocial resources and associations between childhood physical abuse and adult well-being. Journals of Gerontology: Psychological Sciences 65B, 425-433.

Shmotkin D and Litwin H (2009) Cumulative adversity and depressive symptoms among older adults in Israel: the differential roles of self-oriented versus other-oriented events of potential trauma. Social Psychiatry and Psychiatric Epidemiology 44, 989-997.

Shrira A (2012) The effect of lifetime cumulative adversity on change and chronicity in depressive symptoms and quality of life in older adults. International Psychogeriatrics 24, 1988-1997.

Shrira A (2014) Greater age-related decline in markers of physical, mental and cognitive health among Israeli older adults exposed to lifetime cumulative adversity. Aging \& Mental Health 18, 610-618.

Slavich GM and Irwin MR (2014) From stress to inflammation and major depressive disorder: a social signal transduction theory of depression. Psychological Bulletin 140, 774-815.

Steffick DE (2000) Documentation of Affective Functioning Measures in the Health and Retirement Study. Survey Research Center, University of Michigan. Available at https:/hrs.isr.umich.edu/sites/default/files/ biblio/dr-005.pdf.

Steptoe A, Breeze E, Banks J and Nazroo J (2012) Cohort profile: the English Longitudinal Study of Ageing. International Journal of Epidemiology 42, 1640-1648.

Stone J, Evandrou M and Falkingham J (2013) The transition to living alone and psychological distress in later life. Age and Ageing 42, 366-372.

Stone J, Evandrou M, Falkingham J and Vlachantoni A (2015) Women's economic activity trajectories over the life course: implications for the self-rated health of women aged 64+ in England. Journal of Epidemiology and Community Health 69, 873-879. 
Taylor SE, Klein CL, Lewis BP, Gruenewald TL, Gurung RAR and Updegraff JA (2000) Biobehavioral responses to stress in females: tend-and-befriend, not fight-or-flight. Psychological Review 107, 411-429.

Utz RL, Caserta M and Lund D (2012) Grief, depressive symptoms, and physical health among recently bereaved spouses. The Gerontologist 52, 460-471.

Wainwright NW and Surtees PG (2002) Childhood adversity, gender and depression over the life-course. Journal of Affective Disorders 72, 33-44.

Ward K, Medina J, Mo M and Cox K (2009) ELSA Wave Three: Life History Interview. A User Guide to the Data. London: NatCen.

Wilkinson R and Pickett K (2009) The Spirit Level: Why Equality is Better for Everyone. London: Penguin Books.

World Health Organization (2017) Depression and Other Common Mental Disorders: Global Health Estimates. Geneva: World Health Organization.

Zethof D, Nagelhout GE, Rooij M, Driezen P, Fong GT, Putte B, Hummel K, Vries H, Thompson ME and Willemsen MC (2016) Attrition analysed in five waves of a longitudinal yearly survey of smokers: findings from the ITC Netherlands survey. The European Journal of Public Health 26, 693-699.

Zoellner LA, Goodwin ML and Foa EB (2000) PTSD severity and health perceptions in female victims of sexual assault. Journal of Traumatic Stress 13, 635-649.

Cite this article: Falkingham J, Evandrou M, Qin M, Vlachantoni A (2020). Accumulated lifecourse adversities and depressive symptoms in later life among older men and women in England: a longitudinal study. Ageing \& Society 40, 2079-2105. https://doi.org/10.1017/S0144686X19000461 